\title{
Mechanical properties of reactively flame retarded cyanate ester/epoxy resin blends and their carbon fibre reinforced composites
}

\author{
A. Toldy ${ }^{1 *}$, P. Niedermann ${ }^{1}$, G. Szebényi ${ }^{1,2}$, B. Szolnoki ${ }^{3}$ \\ ${ }^{1}$ Department of Polymer Engineering, Faculty of Mechanical Engineering, Budapest University of Technology and \\ Economics, H-1111 Budapest, Müegyetem rkp. 3, Hungary \\ ${ }^{2}$ MTA-BME Research Group for Composite Science and Technology, H-1111 Budapest, Mủegyetem rkp. 3., Hungary \\ ${ }^{3}$ Department of Organic Chemistry and Technology, Faculty of Chemical Technology and Biotechnology, Budapest \\ University of Technology and Economics, H-1111 Budapest, Budafoki út 8.
}

Received 8 June 2016; accepted in revised form 25 July 2016

\begin{abstract}
Cyanate ester/epoxy resin (CE/EP) carbon fibre reinforced composites consisting of diglycidyl ether of bisphenol A (DGEBA) and novolac type cyanate ester (CE) were prepared and reactively flame retarded using epoxy functional adduct of DGEBA and 9,10-dihydro-9-oxa-10-phosphaphenanthrene-10-oxide (DOPO). Effect of cyanate ester and flame retardant (FR) ratio was determined on matrix viscosity, matrix and composite glass transition temperature $\left(T_{\mathrm{g}}\right)$, as well as composite mechanical properties including storage modulus, tensile, bending, interlaminar shear and Charpy impact properties. Although the epoxy resin (EP) and FR decreased the $T_{\mathrm{g}}$, even the flame retarded CE/EP blends had at least $22^{\circ} \mathrm{C}$ higher $T_{\mathrm{g}}$ than the benchmark DGEBA composite. As for the mechanical properties, as a result of higher interlaminar shear strength suggesting better fibre-matrix adhesion, the CE/EP blends managed to over-perform the reference CE in most cases: The $2 \%$ phosphorus (P)-containing CE/EP composite had 25\% higher tensile strength than the CE reference. The bending strength of the blends remained in the same range as the reference, while the impact resistance significantly increased in comparison to CE, especially in flame retarded composites.
\end{abstract}

Keywords: mechanical properties, flame retardancy, cyanate ester, epoxy resin, carbon fibre reinforced composites

\section{Introduction}

Even in case of high performance thermosetting polymer materials as cyanate esters and epoxy resins the flame retardancy is still an issue to be solved, particularly in advanced sectors with strict safety requirements as electrical and aeronautical industry. However, the addition of flame retardants usually decreases the glass transition temperature and mechanical properties of the polymers [1]. One possibility to minimize these effects is to apply reactive flame retardants, which can be chemically incorporated into the polymer structure. This approach offers further advantages: as the flame retardant does not migrate to the surface of the matrix either during high temperature processing or application, it provides more stable effect compared to additive flame retardants and lower ratio is sufficient to achieve the same level of flame retardancy [2]. The increasing focus on the health and environmental compatibility of flame retardants also facilitated the headway of this reactive approach, in particular many organophosphorus reactive flame retardants were developed in the recent years [3-6]. Another way to compensate the effect of flame retardants is to form blends with another polymer possessing high glass transition temperature, thermally stable backbone and outstanding me-

*Corresponding author, e-mail: atoldy@mail.bme.hu (C) BME-PT 
chanical properties. Again, instead of simple blend formation reactive blending resulting in primary chemical bonds between the polymers is preferred. For these reasons epoxy resins are often blended with cyanate esters [7-10], which can be applied instead of the commonly applied amine or anhydride type hardeners. This way cyanate esters can be used as multifunctional reactive modifiers increasing the glass transition temperature, and improving the thermal stability and mechanical properties of flame retarded epoxy resins.

In $\mathrm{CE} / \mathrm{EP}$ systems either the $\mathrm{EP}[11,12]$ or the $\mathrm{CE}$ component [13-15] can contain the phosphorus $(\mathrm{P})$ -containing flame retardant unit, but separate P-containing reactive modifiers (mostly with $-\mathrm{OH}$ [16] and $-\mathrm{NH}_{2}$ functions [17]) can be applied as well. These articles studied the flame retardancy results of P-containing CE/EP or CE, along with the effect on glass transition temperature and in some cases on modulus only in polymer matrices. To the extent of our knowledge, no articles have been published yet on the effects of phosphorus flame retardants on glass transition temperature and mechanical properties in $\mathrm{CE} / \mathrm{EP}$ fibre reinforced composites, therefore our current study aims at filling in this gap.

In particular, in this work the EP component, DGEBA was pre-reacted with DOPO in order to obtain an epoxy functional reactive flame retardant, and a novolac type, high glass transition temperature $\mathrm{CE}$ was blended with it. As the flame retardants generally decrease the glass transition temperature of EPs, the hybrid system consisting of $\mathrm{CE}, \mathrm{EP}$ and reactive flame retardant was made in order to reach higher glass transition temperature than in case of flame retarded EP alone.

Based on flame retardancy results of these CE/EP systems (published previously by the authors [18]), the best performing blends were chosen, and the effect of CE and flame retardant ratio was determined on viscosity, glass transition temperature $\left(T_{\mathrm{g}}\right)$ and dynamic mechanical properties. From these best performing blends also reactively flame retarded CE/EP carbon fibre reinforced composites were made and their dynamic mechanical, tensile, bending, interlaminar shear strength and Charpy impact properties were tested and compared to CE and EP benchmarks.

\section{Materials and methods}

\subsection{Materials}

Novolac type cyanate ester (Primaset PT-30) was acquired from Lonza Ltd. (Basel, Switzerland).

Diglycidyl ether of bisphenol A (DGEBA, Ipox ER 1010) with $188 \mathrm{~g} /$ eq epoxy equivalent weight was obtained from IPOX Chemicals Ltd. (Budapest, Hungary).

As reactive flame retardant 9,10-dihydro-9-oxa-10phosphaphenanthrene-10-oxide (DOPO, Struktol Polydis 3710, properties: molecular mass: $216.17 \mathrm{~g} / \mathrm{mol}$, melting point: $116^{\circ} \mathrm{C}$ ) was used supplied by Struktol Gmbh (Hamburg, Germany).

In order to form a phosphorus-containing epoxy component, DOPO was reacted with DGEBA in 1:1 molar ratio. Before the reaction DOPO was kept at $85^{\circ} \mathrm{C}$ for $12 \mathrm{~h}$, in order to eliminate the traces of moisture. DGEBA was kept under vacuum at $110^{\circ} \mathrm{C}$ to remove air and traces of moisture, and after adding DOPO, the mixture was stirred at $160^{\circ} \mathrm{C}$ for $5 \mathrm{~h}$. After cooling to room temperature a solid adduct was obtained. This synthesis, based on the method of Wang and Lin [19], was published by the authors previously [18]. The main advantage of the adduct formation is, that this way the highly intensive reaction between DOPO and PT-30, furthermore carbamate and consequent $\mathrm{CO}_{2}$ formation from $\mathrm{CE}$ due to water traces present in DOPO (despite careful drying) can be avoided. Due to controlled reaction conditions and stoichiometry, an oxirane functional adduct is formed, which reacts the same way as DGEBA with PT-30 (main reactions: trimerization of cyanates, insertion of oxiranes into the cyanurate, isomerization of alkylsubstituted triazines and formation of oxalidinones from isocyanurates and glycidyl ethers [20]).

As hardener methyl-tetrahydrophthalic-anhydride (Aradur 917 -AR917) was applied with 1-methylimidazole (DY070) accelerator by Huntsman Advanced Materials (Basel, Switzerland). The equivalent mass of the anhydride type curing agent, calculated from its molecular mass, was $160 \mathrm{~g} / \mathrm{eq}$. The accelerator was applied in 2 mass \% related to the mass of DGEBA. The chemical structures of the used polymer components are shown in Figure 1.

As fibre reinforcement Zoltek Panex 35 type unidirectional carbon weave with $300 \mathrm{~g} / \mathrm{m}^{2}$ areal weight provided by Zoltek Ltd. (Nyergesújfalu, Hungary) was applied. 
<smiles>N#COc1cccc(-c2cccc(OC#N)c2)c1</smiles><smiles>CC1CCC2=C(C1)C(=O)OC2=O</smiles>

AR917<smiles></smiles><smiles></smiles><smiles>O=C(OCC(O)COc1ccc(C2(c3ccc(OCC4CO4)cc3)CC2)cc1)OP1(=O)Oc2ccccc2-c2ccccc21</smiles>

Figure 1. Chemical structures of the used polymer components

\subsection{Methods}

\subsubsection{Sample preparation}

Besides the reference $\mathrm{CE}, \mathrm{EP}$ and $\mathrm{CE} / \mathrm{EP}$ matrices, flame retarded CE/EP matrices with 2 and 3 mass $\%$ phosphorus were prepared using the synthesized DGEBA - DOPO adduct. The composition of the composite matrices is summarized in Table 1.

Polymer matrix specimens for the mechanical investigations were made by resin moulding with a vertical moulding tool. For the preparation of matrix specimens for flame retardancy testing heat resistant silicone moulds were used of appropriate size. The composite laminates were made by hand lamination followed by press moulding. Each carbon weave layer was separately impregnated, in case of high viscosity matrices the polymer and the mould were heated to $80^{\circ} \mathrm{C}$. The prepared laminates were put under compression with 25 bar pressure in T30 type platen press (Metal Fluid Engineering s. r. 1., Verdello Zingonia, Italy) to achieve high and uniform fibre content in the composites. For flame retardancy meas- urements $4 \mathrm{~mm}$ thick specimens were made using $[0]_{10}$ of carbon weave, while for mechanical tests $2 \mathrm{~mm}$ thick laminates were made with $[0]_{5}$ layup. The heat treatment was carried out during pressing. Samples containing PT-30 were cured $1 \mathrm{~h}$ at $150^{\circ} \mathrm{C}$, $3 \mathrm{~h}$ at $200^{\circ} \mathrm{C}$ and $1 \mathrm{~h} 260^{\circ} \mathrm{C}$ according to the suggestion of CE supplier. In case of DGEBA the heat treatment consisted of a $1 \mathrm{~h} 80^{\circ} \mathrm{C}$ and $3 \mathrm{~h} 140^{\circ} \mathrm{C}$ isothermal step. The measured fibre content of the composites was in the range of 50-55 mass\%.

\subsubsection{Parallel plate rheometry}

Viscosity was determined by parallel plate rheometry using AR2000 device from TA Instruments (New Castle, DE, USA) in the range of $25-80^{\circ} \mathrm{C}$, with $5^{\circ} \mathrm{C} / \mathrm{min}$ temperature ramp, applying $40 \mathrm{~mm}$ diameter plate and $150 \mu \mathrm{m}$ gap between the plates.

\subsubsection{Flame retardant characterization}

The fire behaviour of the reference and flame retarded systems was characterized by limiting oxygen

Table 1. Composition of the CE, EP and CE/EP composite matrices

\begin{tabular}{|c|c|c|c|c|c|}
\hline & \multicolumn{5}{|c|}{$\begin{array}{c}\text { Sample composition } \\
\text { [mass\%] }\end{array}$} \\
\hline & PT-30 & DGEBA & DOPO & AR917 & DY070 \\
\hline \multicolumn{6}{|c|}{ Reference samples } \\
\hline PT-30 & 100 & - & - & - & - \\
\hline DGEBA & - & 52.3 & - & 47.1 & 0.6 \\
\hline $20 \%$ PT-30 - $80 \%$ DGEBA & 20 & 80 & - & - & - \\
\hline $40 \%$ PT-30 - $60 \%$ DGEBA & 40 & 60 & - & - & - \\
\hline \multicolumn{6}{|c|}{ Flame retarded samples } \\
\hline $40 \%$ PT- 30 - DGEBA - DOPO $2 \%$ P & 40 & 46.1 & 13.9 & - & - \\
\hline $40 \%$ PT-30 - DGEBA - DOPO 3\% P & 40 & 39.1 & 20.9 & - & - \\
\hline
\end{tabular}


index measurements (LOI, according to ASTM D2863). The LOI value expresses the minimum volume fraction of oxygen in a mixture of oxygen and nitrogen that supports flaming combustion of a material under specified test conditions.

Standard UL-94 flammability tests (according to ASTM D3081 and ASTM D-635, respectively) were also carried out in order to classify the samples based on their flammability in horizontal and vertical test setups.

Mass loss calorimeter tests were carried out by an instrument made by FTT Inc. (East Grinstead, UK) according to ISO 13927 standard method. Specimens $(100 \times 100 \times 4 \mathrm{~mm})$ were exposed to a constant heat flux of $50 \mathrm{~kW} / \mathrm{m}^{2}$ and ignited. Heat release values and mass reduction were continuously recorded during burning.

\subsubsection{Dynamic mechanical analysis (DMA)}

For the investigations of the dynamic mechanical properties and for the determination of the glass transition temperature $\left(T_{\mathrm{g}}\right)$ values DMA tests were carried out in three point bending setup with TA Q800 device of TA Instruments (New Castle, DE, USA). The temperature range was $0-260^{\circ} \mathrm{C}$ (in case of pure CE samples $0-400^{\circ} \mathrm{C}$ ) with $3{ }^{\circ} \mathrm{C} / \mathrm{min}$ heat rate. The frequency was $1 \mathrm{~Hz}$. The size of the specimens was $55 \times 10 \times 2 \mathrm{~mm}$ (length $\times$ width $\times$ thickness), and the support span was $50 \mathrm{~mm}$. The amplitude was strain controlled with $0.1 \%$ relative strain. From the results glass transition temperature based on the $\tan \delta$ peaks $\left(T_{\mathrm{g}}\right)$ and storage modulus $\left(E^{\prime}\right)$ values at 25 and $75^{\circ} \mathrm{C}$ were determined by the software of the DMA device (TA Instruments Universal Analysis 2000 4.7A version).

\subsubsection{Tensile test}

Tensile tests were carried out to determine the composites tensile strength and tensile modulus values $\left(E_{\mathrm{m}}\right)$ by a Zwick Z250 (Ulm, Germany) type computer controlled universal tester, equipped with a $20 \mathrm{kN}$ capacity load cell. Based on EN ISO 527 the specimen size was $140 \times 10 \times 2 \mathrm{~mm}$ (length $\times$ width $\times$ thickness). The test speed was $2 \mathrm{~mm} / \mathrm{min}$, and the initial test length was $80 \mathrm{~mm}$. During the test, force and displacement values were recorded and the tensile parameters were calculated according to the standard. In each case 5 parallel tests were carried out.

\subsubsection{Bending test}

Bending tests were carried out in three point bending setup to determine the composites flexural strength and flexural modulus values by a Zwick Z250 (Ulm, Germany) type computer controlled universal tester, equipped with a $20 \mathrm{kN}$ capacity load cell with standard three point bending fixtures. The size of the specimens, based on EN ISO 14125 was $100 \times 10 \times 2 \mathrm{~mm}$ (length $\times$ width $\times$ thickness). The test speed was $5 \mathrm{~mm} / \mathrm{min}$, and the span length was $80 \mathrm{~mm}$. During the test, force and deflection values were recorded and the bending parameters were calculated according to the standard. In each case 5 parallel tests were carried out.

\subsubsection{Interlaminar shear test}

According to EN ISO 14130 interlaminar shear tests were carried out on $5-5$ specimens with $20 \times 10 \times$ $2 \mathrm{~mm}$ size (length $\mathrm{x}$ width $\mathrm{x}$ thickness) by a Zwick Z020 (Ulm, Germany) universal tester. The support span was $10 \mathrm{~mm}$ and the test speed was $1 \mathrm{~mm} / \mathrm{min}$. From the registered force-deflection results apparent interlaminar shear strength was calculated and compared.

\subsubsection{Charpy impact test}

Charpy impact tests were carried out according to EN ISO 179-1 by a normal impact on unnotched specimens of $80 \mathrm{~mm}$ length, $10 \mathrm{~mm}$ width and $2 \mathrm{~mm}$ thick with a Ceast Resil Impactor Junior (Torino, Italy) instrumented pendulum equipped with a $2 \mathrm{~J}$ hammer using $2.9 \mathrm{~m} / \mathrm{s}$ impact velocity, with $150^{\circ}$ starting angle and $62 \mathrm{~mm}$ support span on 5-5 specimens from each sample. The force-time curves were registered by a Ceast DAS 8000 data acquisition unit and the Charpy impact energy was calculated and compared.

\section{Results and discussion}

\subsection{Viscosity of polymer matrices}

One major aspect of the processing of resin systems is their viscosity, therefore prior to composite preparation viscosity of the polymer matrices was determined in the function of temperature. According to Hay [21] for resin injection $100-300 \mathrm{mPa} \cdot \mathrm{s}$, for pultrusion $400-800 \mathrm{mPa} \cdot \mathrm{s}$, while for filament winding viscosity of $800-2000 \mathrm{mPa} \cdot \mathrm{s}$ is recommended. Cyanate esters are often processed by filament winding, where the filaments are immersed into a heat- 


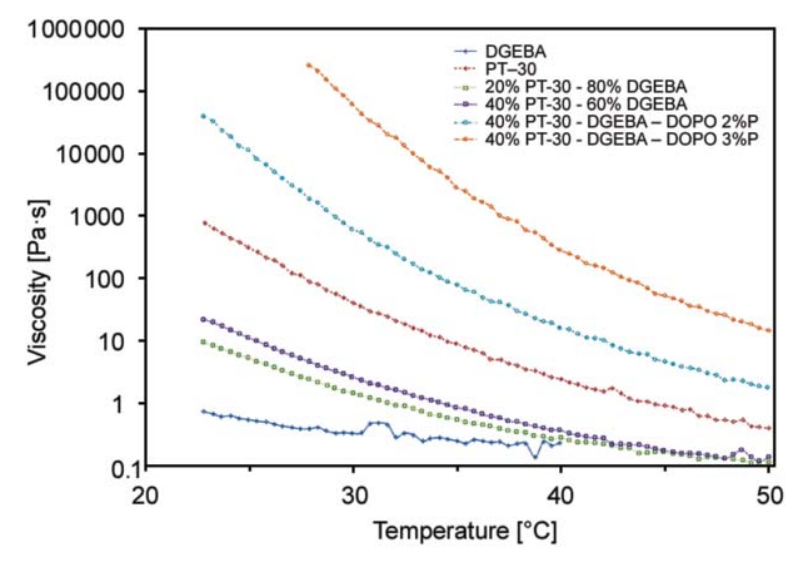

Figure 2. Viscosity of the CE and EP references and CE/EP blends in the temperature range of $25-80^{\circ} \mathrm{C}$

able resin bath allowing the reduction of the matrix viscosity by increasing its temperature. The viscosity of the $\mathrm{CE}$ and $\mathrm{EP}$ references and $\mathrm{CE} / \mathrm{EP}$ blends in the temperature range of $25-80^{\circ} \mathrm{C}$ can be seen in Figure 2.

By increasing the amount of CE in the blends, the viscosity increased, as expected. Furthermore, the addition of solid DOPO-DGEBA adduct significantly increased the viscosity as well. By increasing the temperature the viscosity of the matrices showed a monotone decreasing tendency.

According to the viscosity values at $80^{\circ} \mathrm{C}$ (Table 2) the samples containing 3 mass $\%$ phosphorus can be rather processed by hot pressing, Blends containing 2 mass \% phosphorus are suitable for filament winding as well.
Table 2. Viscosity of the CE and EP references and CE/EP blends at $80^{\circ} \mathrm{C}$

\begin{tabular}{|l|c|}
\hline \multicolumn{1}{|c|}{ Sample } & $\begin{array}{c}\text { Viscosity } \\
{[\mathbf{m P a} \cdot \mathbf{s}]}\end{array}$ \\
\hline PT-30 & 400 \\
\hline DGEBA & $233^{*}$ \\
\hline $20 \%$ PT-30 - 80\% DGEBA & 107 \\
\hline $40 \%$ PT-30 - 60\% DGEBA & 113 \\
\hline $40 \%$ PT-30 - DGEBA - DOPO 2\%P & 1623 \\
\hline $40 \%$ PT-30 - DGEBA - DOPO 3\%P & 14780 \\
\hline${ }^{*}$ at $60{ }^{\circ}$ C-on due to lower gel time & \\
\end{tabular}

Based on these results hand lamination followed by hot pressing was chosen as composite preparation method, as it provides high fibre content and excellent reproducibility.

\subsection{Flame retardancy of polymer matrices and composites}

In order to be able to judge the overall performance of the CE/EP systems, their LOI, UL-94 and most important mass loss calorimetry results were summarized in Table 3. The flame retardancy results of the CE/EP matrices itself along with the results of polymer composites made thereof are discussed in detail elsewhere [18].

The addition of CE to EP significantly increased the LOI value, however it was not sufficient to improve the HB UL-94 rate of the samples. All blends consisting of EP, CE and phosphorus-containing flame retardant reached the V-0 UL-94 classification and

Table 3. LOI, UL-94 and mass loss calorimetry results of the composites made of CE and EP references and their blends

\begin{tabular}{|c|c|c|c|c|c|c|}
\hline & $\begin{array}{c}\text { LOI } \\
{[\mathrm{V} / \mathrm{V} \%]}\end{array}$ & UL-94* & $\begin{array}{c}\text { TTI } \\
{[\mathbf{s}]}\end{array}$ & $\begin{array}{c}\text { pHRR } \\
{\left[\mathrm{kW} / \mathrm{m}^{2}\right]}\end{array}$ & $\begin{array}{c}\text { THR } \\
{\left[\mathrm{MJ} / \mathrm{m}^{2}\right]}\end{array}$ & $\begin{array}{c}\text { Residue } \\
\text { [mass\%] }\end{array}$ \\
\hline \multicolumn{7}{|c|}{ Matrix sample } \\
\hline PT-30 & 30 & $\mathrm{HB}$ & 26 & 156 & 15.5 & 48 \\
\hline DGEBA & 23 & HB (17.1 \pm 2$)$ & 40 & 743 & 91.0 & 0 \\
\hline $20 \%$ PT- $30-80 \%$ DGEBA & 33 & HB & 50 & 471 & 59.6 & 0 \\
\hline $40 \%$ PT-30 - 60\% DGEBA & 28 & HB & 50 & 238 & 55.1 & 14 \\
\hline $40 \%$ PT-30 - DGEBA - DOPO 2\%P & 43 & $\mathrm{~V}-0$ & 53 & 195 & 36.3 & 23 \\
\hline $40 \%$ PT-30 - DGEBA - DOPO 3\%P & 45 & $\mathrm{~V}-0$ & 44 & 234 & 47.5 & 22 \\
\hline \multicolumn{7}{|c|}{ Composite sample } \\
\hline PT-30 & 58 & $\mathrm{~V}-0$ & 80 & 84 & 9.8 & 81 \\
\hline DGEBA & 33 & $\mathrm{HB}$ & 55 & 176 & 37.9 & 50 \\
\hline $20 \%$ PT-30 - 80\% DGEBA & 41 & HB & 51 & 162 & 29.9 & 61 \\
\hline $40 \%$ PT-30 - $60 \%$ DGEBA & 42 & $\mathrm{~V}-0$ & 87 & 134 & 21.8 & 70 \\
\hline $40 \%$ PT-30 - DGEBA - DOPO 2\%P & 46 & $\mathrm{~V}-0$ & 72 & 101 & 20.1 & 67 \\
\hline $40 \%$ PT-30 - DGEBA - DOPO 3\%P & 48 & $\mathrm{~V}-0$ & 70 & 84 & 18.7 & 67 \\
\hline
\end{tabular}

*in parenthesis the horizontal burning rate is showed, where measurable

LOI: limiting oxygen index, TTI: time to ignition, pHRR: peak of heat release rate, THR: total heat released

Flame retarded samples are highlighted in grey $(2 \% \mathrm{P})$ and dark grey $(3 \% \mathrm{P})$ 
exhibited intensive intumescent charring and increased residual mass. Although the carbon fibre reinforcement plies hinder the solid phase intumescent mechanism of the phosphorus flame retardant [22], as the reinforcement itself is inflammable under the conditions of the flame retardancy tests, the composite specimens showed even better flame retardant properties than the polymer matrices alone. In composite specimens 40 mass $\%$ of PT-30 alone was sufficient to reach the V-0 UL-94 rate. By increasing the amount of $\mathrm{CE}$ and DOPO, the LOI increased and the pHRR values showed further decrease. The $40 \%$ PT30 - DGEBA - DOPO 3\%P composite had the same pHRR value, $84 \mathrm{~kW} / \mathrm{m}^{2}$ as the PT-30 reference composite.

\subsection{Dynamic mechanical analysis of polymer matrices and composites}

Storage modulus curves of the $\mathrm{CE}$ and $\mathrm{EP}$ references and CE/EP blends are displayed in Figure 3, while that of the composites can be seen in Figure 4. Glass transition temperature based on the $\tan \delta$ peaks $\left(T_{\mathrm{g}}\right)$

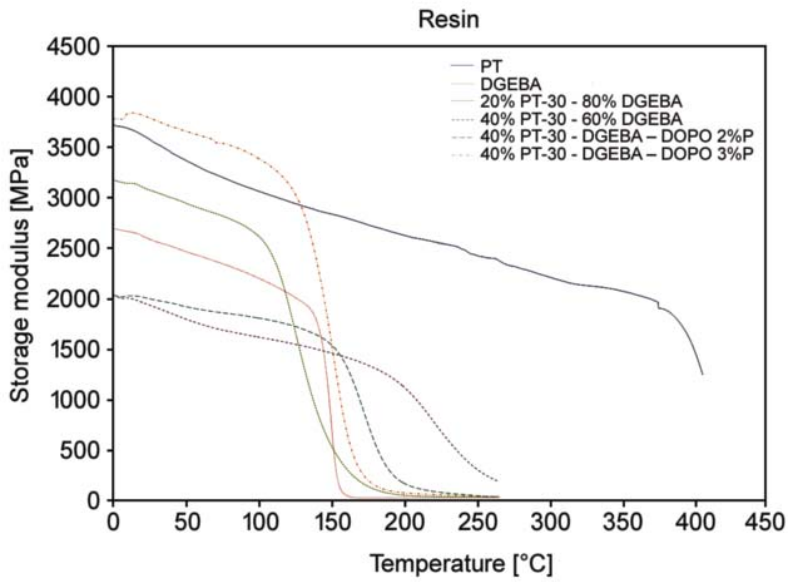

Figure 3. Storage modulus of the $\mathrm{CE}$ and $\mathrm{EP}$ references and $\mathrm{CE} / \mathrm{EP}$ blends in the temperature range of 25 $260^{\circ} \mathrm{C}$ (in case of pure $\mathrm{CE} 25-400^{\circ} \mathrm{C}$ )



Figure 4. Storage modulus of the CE and EP reference and $\mathrm{CE} / \mathrm{EP}$ blend composites in the temperature range of $25-260^{\circ} \mathrm{C}$ (in case of pure $\mathrm{CE} 25-400^{\circ} \mathrm{C}$ )

and storage modulus $\left(E^{\prime}\right)$ values at 25 and $75^{\circ} \mathrm{C}$ are shown in Table 4.

In case of resin samples by increasing the temperature the storage moduli showed a decreasing tendency, while in case of composite samples it remained in the same range at least up to $75^{\circ} \mathrm{C}$. As for the CE/EP resin blends, the 20\% PT-30 - 80\% DGEBA had higher storage modulus up to $115^{\circ} \mathrm{C}$, while the 40\% PT-30 - 60\% DGEBA blend showed better properties than DGEBA only above $140^{\circ} \mathrm{C}$, similarly to its flame retarded version with $2 \% \mathrm{P}$. However, the $40 \%$ PT-30 - DGEBA - DOPO 3\%P matrix sample performed better than DGEBA in the whole temperature range, and had even higher storage modulus than $\mathrm{CE}$ up to $125^{\circ} \mathrm{C}$, which may be explained by the relative stoichiometric excess of PT-30 (related to the amount of oxirane groups present in DGEBA and DOPO-DGEBA components in the sample). In case of composite samples the $20 \%$ PT- $30-80 \%$ DGEBA blend had higher storage modulus than CE up to $90^{\circ} \mathrm{C}$ and higher than DGEBA up to $105^{\circ} \mathrm{C}$. The $40 \%$ PT-30 - $60 \%$ DGEBA composite per-

Table 4. Glass transition temperature $\left(T_{\mathrm{g}}\right)$ and storage modulus values at 25 and $75^{\circ} \mathrm{C}$ of $\mathrm{CE} / \mathrm{EP}$ matrices and composites determined by DMA

\begin{tabular}{|c|c|c|c|c|c|c|}
\hline \multirow[b]{2}{*}{ Sample } & \multicolumn{2}{|c|}{$\begin{array}{l}\text { Glass transition temperature } \\
\qquad\left[{ }^{\circ} \mathrm{C}\right]\end{array}$} & \multicolumn{2}{|c|}{$\begin{array}{l}\text { Storage modulus at } 25^{\circ} \mathrm{C} \\
{[\mathrm{MPa}]}\end{array}$} & \multicolumn{2}{|c|}{$\begin{array}{c}\text { Storage modulus at } 75^{\circ} \mathrm{C} \\
{[\mathrm{MPa}]}\end{array}$} \\
\hline & Matrix & Composite & Matrix & Composite & Matrix & Composite \\
\hline PT-30 & 401 & 394 & 3572 & 72407 & 3196 & 71908 \\
\hline DGEBA & 155 & 145 & 2585 & 69691 & 2343 & 69407 \\
\hline $20 \%$ PT-30 - 80\% DGEBA & 172 & 145 & 3071 & 92311 & 2815 & 91420 \\
\hline $40 \%$ PT-30 - $60 \%$ DGEBA & 247 & 249 & 1932 & 73150 & 1686 & 73360 \\
\hline $40 \%$ PT-30 - DGEBA - DOPO 2\%P & 188 & 187 & 1995 & 55967 & 1856 & 55537 \\
\hline $40 \%$ PT-30 - DGEBA - DOPO 3\%P & 165 & 167 & 3784 & 65882 & 3534 & 65378 \\
\hline
\end{tabular}


formed similarly as CE up to $200^{\circ} \mathrm{C}$ and outperformed DGEBA in the whole temperature range. The flame retarded composites showed somewhat lower storage modulus than DGEBA (except the 140$165^{\circ} \mathrm{C}$ range in case of $40 \%$ PT-30 - DGEBA DOPO $3 \% \mathrm{P}$ composite, and the $140-190^{\circ} \mathrm{C}$ range in case of $40 \%$ PT-30 - DGEBA - DOPO 2\%P), most probably due to lower fibre-matrix adhesion (see the interlaminar shear properties in chapter 3.4.).

As for the glass transition temperatures (Table 4), in case of resin samples the $T_{\mathrm{g}}$ of the blends increased with increasing amount of CE. Compared to $40 \%$ PT-30 - 60\% DGEBA sample, the inclusion of flame retardants decreased the $T_{\mathrm{g}}$, most probably due to lower crosslinking density, however it was still above the $T_{\mathrm{g}}$ of DGEBA. In case of composite samples the $T_{\mathrm{g}}$ decreased in CE and EP reference samples and in $20 \%$ PT-30 - $80 \%$ DGEBA sample, while in $40 \%$ PT30 containing composites, including the flame retarded ones, practically it remained the same value as in case of the matrix samples. Compared to DGEBA, the $40 \%$ PT-30 - DGEBA - DOPO 2\%P composite showed $42{ }^{\circ} \mathrm{C}$ increase, while the $40 \%$ PT- 30 DGEBA - DOPO 3\%P composite had still $22^{\circ} \mathrm{C}$ higher $T_{\mathrm{g}}$.

\subsection{Tensile, bending, interlaminar shear and Charpy impact properties of polymer composites}

Tensile properties of the CE and EP reference composites and CE/EP blend composites are shown in
Table 5. According to the tensile test results, the inclusion of EP significantly increased the tensile strength of the rigid CE. More surprisingly, by adding DOPO-DGEBA adduct to the $40 \%$ PT-30 - 60\% DGEBA matrix, the tensile strength of the $2 \%$ P-containing composite increased even further, and in case of 3\% P-containing sample it still remained over the value of the $\mathrm{CE}$ reference. This amelioration may be attributed to better fibre-matrix adhesion and to the reactive nature of the flame retardant: by incorporating it by primary chemical bonds to the matrix itself, it does not migrate to the matrix surface either during high temperature processing or application. The strain at break increased to some extent in all blends containing DGEBA in comparison to the reference CE, decreasing the rigidity of it. The highest tensile modulus was reached in case of $20 \%$ PT- $30-80 \%$ DGEBA, higher than the moduli of the blend components themselves. By adding DOPO-DGEBA adduct to the system, the tensile modulus slightly decreased.

Flexural properties of the CE and EP reference composites and CE/EP blend composites are shown in Table 6. According to the results the addition of EP into $\mathrm{CE}$ resulted in slightly higher flexural strength than in case of the reference CE and EP itself. The inclusion of DOPO-DGEBA adduct decreased the flexural strength and modulus, and increased the deformation at break, however taking into account the standard deviation values, the flexural strength and modulus of $40 \%$ PT-30 - DGEBA - DOPO 3\% re-

Table 5. Tensile properties of the CE and EP reference composites and CE/EP blend composites

\begin{tabular}{|l|c|c|c|}
\hline \multicolumn{1}{|c|}{ Composite sample } & $\begin{array}{c}\text { Tensile strength } \\
{[\mathbf{M P a}]}\end{array}$ & $\begin{array}{c}\text { Strain at break } \\
{[\%]}\end{array}$ & $\begin{array}{c}\text { Tensile modulus } \\
\text { [GPa] }\end{array}$ \\
\hline PT-30 & $689.2 \pm 100.9$ & $4.43 \pm 0.60$ & $27.7 \pm 0.7$ \\
\hline DGEBA & $912.6 \pm 45.7$ & $5.35 \pm 0.43$ & $26.8 \pm 2.4$ \\
\hline $20 \%$ PT-30 - $80 \%$ DGEBA & $1040.9 \pm 43.0$ & $5.66 \pm 0.22$ & $28.8 \pm 0.2$ \\
\hline $40 \%$ PT-30 - 60\% DGEBA & $844.1 \pm 40.3$ & $5.06 \pm 0.16$ & $25.1 \pm 2.1$ \\
\hline $40 \%$ PT-30 - DGEBA - DOPO 2\%P & $861.2 \pm 54.7$ & $5.73 \pm 0.47$ & $24.9 \pm 0.4$ \\
\hline $40 \%$ PT-30 - DGEBA - DOPO 3\%P & $715.2 \pm 32.4$ & $5.06 \pm 0.19$ & $23.4 \pm 0.2$ \\
\hline
\end{tabular}

Table 6. Flexural properties of the CE and EP reference composites and CE/EP blend composites

\begin{tabular}{|l|c|c|c|}
\hline \multicolumn{1}{|c|}{ Composite sample } & $\begin{array}{c}\text { Flexural strength } \\
{[\mathbf{M P a}]}\end{array}$ & $\begin{array}{c}\text { Deformation at break } \\
{[\%]}\end{array}$ & $\begin{array}{c}\text { Flexural modulus } \\
\text { [GPa] }\end{array}$ \\
\hline PT-30 & $1227.0 \pm 271.1$ & $1.36 \pm 0.03$ & $103.2 \pm 19.5$ \\
\hline DGEBA & $1203.0 \pm 115.9$ & $1.36 \pm 0.09$ & $98.2 \pm 4.3$ \\
\hline 20\% PT-30 - 80\% DGEBA & $1240.1 \pm 114.3$ & $1.36 \pm 0.04$ & $100.1 \pm 10.9$ \\
\hline $40 \%$ PT-30 - 60\% DGEBA & $1238.5 \pm 79.2$ & $1.37 \pm 0.04$ & $98.2 \pm 8.8$ \\
\hline $40 \%$ PT-30 - DGEBA - DOPO 2\%P & $1056.2 \pm 54.1$ & $1.43 \pm 0.02$ & $79.5 \pm 5.0$ \\
\hline $40 \%$ PT-30 - DGEBA - DOPO 3\%P & $1149.0 \pm 96.7$ & $1.45 \pm 0.09$ & $96.0 \pm 10.9$ \\
\hline
\end{tabular}


mained in the same range as in case of $\mathrm{CE}$ and $\mathrm{EP}$ references.

In order to find an explanation for the tensile and flexural properties, the interlaminar shear strength of the composites was determined (Table 7). In accordance with the tensile and bending properties, the interlaminar shear strength values of the CE/EP blends were higher than in case of the CE and EP references. The inclusion of the polar phosphorus-containing flame retardant decreased the interlaminar shear strength, however these values were still well above the value of the reference CE composite.

Charpy impact test is suitable for comparing the impact resistance of the composites. The results of the instrumented Charpy unnotched impact measurements are given in Table 8 . The impact strength of the $20 \%$ PT-30 - $80 \%$ DGEBA blend was practically the same as in case of DGEBA, however, the $40 \%$ PT-30 - 60\% DGEBA blend had even higher impact strength than CE. By increasing the amount of flame retardants, the fracture toughness showed further in-

Table 7. Interlaminar shear strength of the CE and EP reference composites and CE/EP blend composites

\begin{tabular}{|l|c|}
\hline \multicolumn{1}{|c|}{ Sample } & $\begin{array}{c}\text { Interlaminar shear strength } \\
{[\mathbf{M P a}]}\end{array}$ \\
\hline PT-30 & $40.0 \pm 1.3$ \\
\hline DGEBA & $61.3 \pm 1.9$ \\
\hline $20 \%$ PT-30 - 80\% DGEBA & $66.8 \pm 3.1$ \\
\hline $40 \%$ PT-30 - 60\% DGEBA & $68.3 \pm 3.6$ \\
\hline $40 \%$ PT-30 - DGEBA-DOPO 2\%P & $53.4 \pm 2.0$ \\
\hline $40 \%$ PT-30 - DGEBA-DOPO 3\%P & $47.9 \pm 2.1$ \\
\hline
\end{tabular}

Table 8. Charpy impact strength of the CE and EP reference composites and CE/EP blend composites

\begin{tabular}{|l|c|}
\hline \multicolumn{1}{|c|}{ Sample } & $\begin{array}{c}\text { Charpy impact strength } \\
{\left[\mathbf{J} / \mathbf{m m}^{2}\right]}\end{array}$ \\
\hline PT-30 & $90.1 \pm 8.0$ \\
\hline DGEBA & $84.3 \pm 5.2$ \\
\hline $20 \%$ PT-30 - $80 \%$ DGEBA & $84.6 \pm 2.9$ \\
\hline $40 \%$ PT-30 - 60\% DGEBA & $98.3 \pm 32.0$ \\
\hline $40 \%$ PT-30 - DGEBA-DOPO $\%$ P & $99.1 \pm 15.1$ \\
\hline $40 \%$ PT-30 - DGEBA-DOPO 3\%P & $113.7 \pm 14.0$ \\
\hline
\end{tabular}

crease in comparison to $\mathrm{CE}$, meaning that the flame retarded composites are less brittle than the CE/EP blends and CE, EP references.

\section{Conclusions}

Reactively flame retarded cyanate ester/epoxy resin (CE/EP) carbon fibre reinforced composites consisting of diglycidyl ether of bisphenol A (DGEBA), novolac type cyanate ester (CE) and an epoxy functional adduct of DGEBA and 9,10-dihydro-9-oxa-10phosphaphenanthrene-10-oxide (DOPO) were prepared and tested. Influence of cyanate ester and flame retardant addition was determined on matrix viscosity, matrix and composite glass transition temperature $\left(T_{\mathrm{g}}\right)$, as well as composite mechanical properties.

From the tested CE/EP composites, the overall performance of V-0 UL-94 rated ones is summarized in Table 9. As expected, the $T_{\mathrm{g}}$ of the CE composite was the highest, however even the flame retarded $\mathrm{CE} / \mathrm{EP}$ blends had at least $22^{\circ} \mathrm{C}$ higher $T \mathrm{~g}$ than the benchmark DGEBA composite. As for the mechanical properties, the CE/EP blends outperformed the $\mathrm{CE}$ composite in most cases: The addition of EP considerably increased the tensile strength of the rigid $\mathrm{CE}$, more unexpectedly, by adding DOPO-DGEBA adduct to the $40 \%$ PT- $30-60 \%$ DGEBA matrix, the tensile strength of the $2 \%$ P-containing composite reached a $25 \%$ increase compared to the $\mathrm{CE}$ composite. The inclusion of EP into $\mathrm{CE}$ also resulted in slightly higher flexural strength than in case of the reference $\mathrm{CE}$ and $\mathrm{EP}$ itself, which was somewhat decreased by the DOPO-DGEBA adduct. These results may be interpreted by the better fibre-matrix adhesion: the interlaminar shear strength of the $40 \%$ PT$30-60 \%$ DGEBA blend was $70 \%$ higher than in case of the CE reference. Although the inclusion of the polar phosphorus-containing flame retardant decreased the interlaminar shear strength, their values were still high above the value of the $\mathrm{CE}$ composite. The impact strength also increased in comparison to

Table 9. Overall performance of UL-94 V-0 rated CE/EP composite samples (best achieved values are highlighted in bold)

\begin{tabular}{|l|c|c|c|c|c|}
\hline \multicolumn{1}{|c|}{ Composite sample } & $\begin{array}{c}\text { Glass transition } \\
\text { temperature } \\
{\left[{ }^{\circ} \mathbf{C}\right]}\end{array}$ & $\begin{array}{c}\text { Tensile strength } \\
{[\mathbf{M P a}]}\end{array}$ & $\begin{array}{c}\text { Flexural } \\
\text { strength } \\
{[\mathbf{M P a}]}\end{array}$ & $\begin{array}{c}\text { Interlaminar } \\
\text { shear strength } \\
{[\mathbf{M P a}]}\end{array}$ & $\begin{array}{c}\text { Charpy impact } \\
\text { strength } \\
{\left[\mathbf{J} / \mathbf{m m}^{2}\right]}\end{array}$ \\
\hline PT-30 & $\mathbf{3 9 4}$ & $689.2 \pm 100.9$ & $1227.0 \pm 271.1$ & $40.0 \pm 1.3$ & $90.1 \pm 8.0$ \\
\hline $40 \%$ PT-30 - 60\% DGEBA & 249 & $844.1 \pm 40.3$ & $\mathbf{1 2 3 8 . 5} \pm 7 \mathbf{7 9 . 2}$ & $\mathbf{6 8 . 3} \pm \mathbf{3 . 6}$ & $98.3 \pm 32.0$ \\
\hline $40 \%$ PT-30 - DGEBA - DOPO 2\%P & 187 & $\mathbf{8 6 1 . 2} \pm \mathbf{5 4 . 7}$ & $1056.2 \pm 54.1$ & $53.4 \pm 2.0$ & $99.1 \pm 15.1$ \\
\hline $40 \%$ PT-30 - DGEBA - DOPO 3\%P & 167 & $715.2 \pm 32.4$ & $1149.0 \pm 96.7$ & $47.9 \pm 2.1$ & $\mathbf{1 1 3 . 7 \pm 1 4 . 0}$ \\
\hline
\end{tabular}


CE, from all composites the flame retarded ones were the less brittle.

\section{Acknowledgements}

This work is connected to the scientific program of the 'Development of quality-oriented and harmonized $\mathrm{R}+\mathrm{D}+\mathrm{I}$ strategy and functional model at BME' project. The work reported in this paper has been developed in the framework of the project 'Talent care and cultivation in the scientific workshops of BME' project. Andrea Toldy and Gábor Szebényi acknowledge the financial support received through János Bolyai Scholarship of the Hungarian Academy of Science.

\section{References}

[1] Rakotomalala M., Wagner S., Döring M.: Recent developments in halogen free flame retardants for epoxy resins for electrical and electronic applications. Materials, 3, 4300-4327 (2010). DOI: $10.3390 / \mathrm{ma3} 084300$

[2] Toldy A.: Chemically modified flame retardant polymers. Express Polymer Letters, 3, 267 (2009). DOI: $10.3144 /$ expresspolymlett.2009.33

[3] Levchik S. V., Camino G., Luda M. P., Costa L., Muller G., Costes B., Henry Y.: Epoxy resins cured with aminophenylmethylphosphine oxide 1: Combustion performance. Polymers for Advanced Technologies, 7, 823-830 (1996).

DOI: 10.1002/(SICI)1099-1581(199611)7:11<823::AIDPAT498>3.0.CO;2-X

[4] Artner J., Ciesielski M., Walter O., Döring M., Perez R. M., Sandler J. K. W., Altstädt V., Schartel B.: A novel DOPO-based diamine as hardener and flame retardant for epoxy resin systems. Macromolecular Materials and Engineering, 293, 503-514 (2008).

DOI: $10.1002 /$ mame.200700287

[5] Hergenrother P. M., Thompson C. M., Smith J. G., Connell J. W., Hinkley J. A., Lyon R. E., Moulton R.: Flame retardant aircraft epoxy resins containing phosphorus. Polymer, 46, 5012-5024 (2005).

DOI: $10.1016 /$ j.polymer.2005.04.025

[6] Gérard C., Fontaine G., Bourbigot S.: New trends in reaction and resistance to fire of fire-retardant epoxies. Materials, 3, 4476-4499 (2010).

DOI: $10.3390 / \mathrm{ma} 3084476$

[7] Walters R. N., Lyon R. E.: Fire-resistant cyanate esterepoxy blends. Fire and Materials, 27, 183-194 (2003). DOI: $10.1002 /$ fam. 827

[8] Hamerton I., Hay J. N.: Recent developments in the chemistry of cyanate esters. Polymer International, 47, 465-473 (1998).

DOI: 10.1002/(SICI) 1097-0126(199812)47:4<465:: AID-PI88>3.0.CO;2-S
[9] Martin M. D., Ormaetxea M., Harismendy I., Remiro P. M., Mondragon I.: Cure chemo-rheology of mixtures based on epoxy resins and ester cyanates. European Polymer Journal, 35, 57-68 (1999). DOI: $10.1016 / \mathrm{S} 0014-3057(98) 00095-0$

[10] Toldy A.: Cyanate ester resins - 'Old newcomers' among high performance composite materials. Express Polymer Letters, 7, 722 (2013).

DOI: $10.3144 /$ expresspolymlett.2013.69

[11] Ho T-H., Hwang H-J., Shieh J-Y., Chung M-C.: Thermal and physical properties of flame-retardant epoxy resins containing 2-(6-oxido-6H-dibenz $\langle c, e\rangle\langle 1,2\rangle$ oxaphosphorin-6-yl)-1,4-naphthalenediol and cured with dicyanate ester. Polymer Degradation and Stability, 93, 2077-2083 (2008).

DOI: $10.1016 /$ j.polymdegradstab.2008.09.002

[12] Ho T-H., Hwang H-J., Shieh J-Y., Chung M-C.: Thermal, physical and flame-retardant properties of phosphorus-containing epoxy cured with cyanate ester. Reactive and Functional Polymers, 69, 176-182 (2009). DOI: $10.1016 /$ j.reactfunctpolym.2008.12.019

[13] Lin C. H., Lin H. T., Tian Y. W., Dai S. A., Su W. C.: Preparation of phosphinated bisphenol from acid-fragmentation of 1,1,1-tris(4-hydroxyphenyl)ethane and its application in high-performance cyanate esters. Journal of Polymer Science Part A: Polymer Chemistry, 49, 4851-4860 (2011).

DOI: $10.1002 /$ pola. 24936

[14] Lin C. H.: Synthesis of novel phosphorus-containing cyanate esters and their curing reaction with epoxy resin. Polymer, 45, 7911-7926 (2004).

DOI: $10.1016 /$ j.polymer.2004.09.023

[15] Chen X., Liang G., Gu A., Yuan L.: Flame retarding cyanate ester resin with low curing temperature, high thermal resistance, outstanding dielectric property, and low water absorption for high frequency and high speed printed circuit broads. Industrial and Engineering Chemistry Research, 54, 1806-1815 (2015).

DOI: $10.1021 /$ ie 504333 f

[16] Chang H. C., Lin H. T., Lin C. H.: Benzoxazine-based phosphinated bisphenols and their application in preparing flame-retardant, low dielectric cyanate ester thermosets. Polymer Chemistry, 3, 970-978 (2012). DOI: $10.1039 / \mathrm{c} 2$ py00528j

[17] Krishnadevi K., Nirmala Grace A., Alagar M., Selvaraj V.: Development of hexa (aminophenyl)cyclotriphosphazene-modified cyanate ester composites for hightemperature applications. High Performance Polymers, 26, 89-96 (2014). DOI: $10.1177 / 0954008313500058$

[18] Toldy A., Szlancsik Á., Szolnoki B.: Reactive flame retardancy of cyanate ester/epoxy resin blends and their carbon fibre reinforced composites. Polymer Degradation and Stability, 128, 29-38 (2016). DOI: $10.1016 /$ j.polymdegradstab.2016.02.015 
[19] Wang C. S., Lin C. H.: Synthesis and properties of phosphorus-containing epoxy resins by novel method. Journal of Polymer Science Part A: Polymer Chemistry, 37, 3903-3909 (1999).

DOI: $10.1002 /($ SICI)1099-0518(19991101)37:21<3903 $\because$ AID-POLA4 $>3.0 . \mathrm{CO} ; 2-\mathrm{X}$

[20] Bauer M., Bauer J.: Co-reactions of cyanate esters with epoxies. in 'Chemistry and technology of cyanate ester resins' (ed.: Hamerton I.) Chapman and Hall, London, 77-82 (1994).
[21] Hay J. N.: Processing and cure schedules for cyanate ester resins. in 'Chemistry and technology of cyanate ester resins' (ed.: Hamerton I.) Chapman and Hall, London, 151-192 (1994).

[22] Toldy A., Szolnoki B., Marosi Gy.: Flame retardancy of fibre-reinforced epoxy resin composites for aerospace applications. Polymer Degradation and Stability, 96, 371-376 (2011).

DOI: $10.1016 /$ j.polymdegradstab.2010.03.021 